\title{
КОМПЛЕКСНАЯ ПСИХОЛОГО-ИСКУССТВОВЕДЧЕСКАЯ ЭКСПЕРТИЗА ДЕТСКОЙ ПОРНОГРАФИИ
}

\author{
Журавлёва М.О., Янов Д.М. \\ Одесский научно-исследовательский институт судебной экспертизы \\ Министерства юстиции Украины, \\ Одесса, Украина
}

В статье обосновывается необходимость назначения комплексной психолого-искусствоведческой экспертизы в случаях исследования детской порнографии. Анализируются украинское и мировое законодательство, а также и практика проведения экспертиз материалов, содержащих детскую порнографию. Отмечается важность вовлечения в таких случаях эксперта-психолога, квалификация которого позволит определить, воспринимаются ли изображенные лица как дети, так как восприятие является психологической категорией.

Ключевые слова: психолого-искусствоведческая экспертиза, детская порнография, восприятие.

Одной из задач судебной искусствоведческой экспертизы является определение соответствия продукции требованиям законодательства о защите общественной морали, в частности установление принадлежности предоставленных на исследование предметов к продукции порнографического характера [1]. Учитывая специфику таких исследований, в публикациях неоднократно указывалось на то, что они должны иметь комплексный характер, предусматривающий применение специальных знаний из разных областей, в число которых, помимо искусствоведения, входят судебная медицина, судебная психиатрия и психология, исследования программных продуктов, лингвистика и культурология [2, с. $18-24$; 3; 4, с. 127 ; 5, с. 49-50; 6,с. 154; 7, с. 28-34]. На необходимости привлечения эксперта-психолога к исследованиям информации порнографического характера акцентировали внимание некоторые исследователи, поскольку именно психолог может определить целевой критерий создания и сюжетно-смысловую направленность предоставленных на исследование фоото- и видеоматериалов [2, с. 20-21; 3; 4, с. 127; 5, с. 31]. В Методике проведения судебной искусствоведческой экспертизы продукции порнографического характера, которая содержится в Реестре методик судебных экспертиз Министерства юстиции Украины под регистрационным кодом 15.1.12, привлечение эксперта-психолога для проведения комплексных экспертиз не предусмотрено, однако указано, что при исследовании документальных материалов с признаками порнографии, изображающих психическое и физическое насилие над личностью, необходимо привлечение психиатра [5, с. 50].

Наибольшее количество трудностей у эксперта-искусствоведа, который не владеет специальными знаниями для определения возраста лица, изображенного на исследуемых видео или фотографриях, может вызвать исследование детской порнографии.

Стоит отметить, что мировая экспертная практика идентификации детской порнографии не является унифицированной и зависит от законодательства конкретной страны. В частности, в США эта задача является полномочием следственного органа, который может назначить

Адрес для корреспонденции: Янов Дмитрий Миронович, кандидат исторических наук, судебный эксперт Одесского научно-исследовательского института судебных экспертиз Министерства юстиции Украины, адрес: 65011, Украина, г. Одесса, ул. Успенская, 83/85, тел.:+380487221471; e-mail: nv63115@gmail.com. 
компьютерную или судебно-медицинскую экспертизу. В то же время, последняя назначается только в случаях, когда есть сомнения в том, является ли лицо совершеннолетним. Некоторые исследователи указывали на несовершенство такой практики, поскольку к уголовной ответственности привлекались в основном лица, которые обвинялись в хранении материалов со сценами откровенного сексуального поведения с участием детей, не достигших пубертатного возраста, или откровенной демонстрации гениталий, в то время как менее очевидные случаи могли быть отклонены стороной обвинения из-за недостаточности доказательств [8, p. 269-282]. В Великобритании расследованием случаев, связанных с детской порнографией (известных под термином «непристойные образы детей» (indecent images of children)) занимается специальный отдел полиции [9, р. 173-196].

В странах бывшего СССР порядок назначения экспертиз с целью идентификации детской порнографии также не является унифицированным. Например, в Российской Федерации, как и в Украине, исследование таких материалов входит в число задач искусствоведческой экспертизы [10; 11], в Беларуси - культурологической экспертизы, которая входит в группу психиатрических экспертиз [12]. В Казахстане они являются объектом судебно-экспертного психолого-криминалистического исследования, которую проводят эксперты с базовым психологическим образованием [13].

Помимо различий в практике назначения и проведения экспертиз, в законодательстве ряда стран имеются различия в самом определении понятия «детская порнография». Так, в США, Германии, Японии, и ряде других стран под это понятие попадают только реальные изображения детей, задействованных в откровенных сексуальных действиях, в то время как порнографические изображения, созданные без реального участия детей (рисунки или компьютерная графика) не запрещены, за некоторыми исключениями, особенно если материал признан слишком «реалистичным». Однако в большинстве стран запрещены любые изображения детей, задействованных в действиях сексуального характера [14]. Несмотря на это, в законодательстве многих стран до сих пор отсутствует четкое определение понятия «детская порнография» * или синонимического термина, которое было бы залогом решения спорных случаев [16; 17]. Определение понятия «детская порнография» в законодательстве ряда стран, например Австралии, Нидерландов, Российской Федерации и Украины, включает случаи, когда изображенные лица являются совершеннолетними, но воспринимаются как несовершеннолетние лица [18; 19; 20; 21]. Этот же критерий детской порнографии включен в Конвенцию Совета Европы о киберпреступности [22, ст. 9.2.b]. В статье 1 Закона Украины «О защите общественной морали» понятие «детская порнография» определено как изображение любым способом ребенка или лица, выглядящего как ребенок, в реальном или смоделированном откровенно сексуальном образе и/или задействованном в реальном или смоделированном откровенно сексуальном поведении, или любое изображение половых органов ребенка в сексуальных целях [20, ст. 1].

Определение возраста ребенка, безусловно, входит в компетенцию медицинской экспертизы, так как предполагает исследование пропорций тела, развитие вторичных половых признаков и т.д. В то же время, на вопрос: «выглядит ли изображенное лицо как ребенок?», который следует из статьи 1 Закона Украины «О защите общественной морали» и относится к компетенции

\footnotetext{
* Существует мнение, что понятие «детская порнография» является устаревшим и некорректным; вместо него на Западе чаще употребляется понятие «материалы, содержащие сцены сексуального насилия над ребенком» (child sexual abuse material) [15].
} 
эксперта-психолога, является шире вопроса: «является ли изображенное лицо ребенком?», который может решаться экспертами-медиками. Предусматривается, что в тех случаях, когда медицинская экспертиза может не дать ответ на вопрос о принадлежности изображенного лица к детскому или подростковому возрасту из-за недостаточности четких признаков, экспертпсихолог сможет проанализировать влияние изображения на наблюдателя, то есть особенности восприятия человеком фотографий и видеозаписей порнографического характера. По своей сути вопрос, на который будет отвечать эксперт-психолог, является таковым: «кого именно видит человек, когда смотрит это видео и видит ли он ребенка?».

Эксперт-психолог анализирует восприятие, как психический процесс получения субъективного образа объективного мира. А.Н. Леонтьев подчеркивает двойственность понятия восприятие, которое может описывать две составляющие: восприятие как процесс (человек смотрит и воспринимает образ), и как продукт процесса интериоризации образа объективного мира (человек увидел и составил внутренний субъективный образ того, что он видел) [23].

Для определения того, относится ли инорормация, содержащаяся на предоставленных на исследование носителях, к детской порнографии, эксперт-психолог анализирует то, какое впечатление будет оставлять просмотр фото- и видеоматериалов у среднестатистического наблюдателя (зрителя), то есть какой именно образ отражается в субъективном мире человека, который воспринимает фротографию или видео. В частности, необходимо проанализировать следующие составляющие восприятия:

$>$ как воспринимаются лица, которые изображены на видео и фотографиях, с точки зрения их возможного возраста;

$>$ являются ли указанные изображения нечеткими, размытыми, вызывающими сомнения относительно того, какие лица там изображены (какого возраста, пола и т.д.), то есть, являются ли они сложными для восприятия и могут ли быть сложно диффееренцированными (в соответствии с указанными признаками);

> соответствует ли образ "ребенка», который изображен на видео или фоотографриях, общеизвестным стандартам, определяющих «образ ребенка», то есть, отождествляются ли изображения, которые видит человек во время просмотра видео, со следами его памяти, которые объединяют его представления и знания о детях.

В результате анализа этих составляющих, эксперт-психолог может определить, воспринимаются ли изображенные лица как дети, и не возникают ли при восприятии изображений любые сомнения относительно того, что изображенные лица могут быть, например, переодетыми взрослыми, или взрослыми людьми с аномально низким ростом (карликами) и т.д. Среди признаков того, что изображенные лица являются детьми, следует назвать следующие: женские половые органы наряду с отсутствующими вторичными половыми признаками (типичное развитие грудных желез, форма таза, развитие жировой клетчатки, лобковые и паховые волосы), пропорции телосложения, отсутствие отдельных зубов (возникает впечатление, что у ребенка происходит их изменение), специфические для детей движения, когда заметна слабая мелкая моторика рук ребенка или неуклюжесть подростка.

Практика исследования материалов, содержащих сцены детской порнографии, позволяет утверждать, что в пределах экспертной инициативы эксперт-психолог в выводе может также указать на отдельные сцены особенно жестокого обращения с детьми, издевательства над ними: например, если на лице ребенка наблюдаются эмоции страха, горя или отвращения. 
В таком случае есть основания утверждать, что эти сцены являются пропагандой культа насилия и жестокости, и эксперт вправе указать на это в выводе[24, п. 2.1.], что предоставит основание стороне обвинения дополнительно привлечь обвиняемого к ответственности по статье 300 Уголовного кодекса Украины «Ввоз, изготовление или распространение произведений, которые пропагандируют культ насилия и жестокости, расовую, национальную или религиозную нетерпимость и дискриминацию» [25, ст. 300].

То есть, по мнению авторов, исследование восприятия, которое входит в компетенцию экспертапсихолога, является неотъемлемой составляющей проведения экспертизы детской порнографии, что закреплено в статье 1 Закона Украины «О защите общественной морали» словами «выглядит как ребенок». Полагаем, что в случае необходимости разграничения порнографии и детской порнографрии необходимо назначать комплексную психолого-искусствоведческую экспертизу.

Законодательство большинства стран различает понятия «порнографрия» и «детская порнография». Первая категория является либо легальной с определенными ограничениями, либо запрещенной; вторая - запрещенной, но с более суровым наказанием по сравнению с «взрослой порнографрией». И только в некоторых исламских странах, где правовая система основывается на нормах шариата, таких как Иран, Ирак, Саудовская Аравия и Сирия, запрещенной является любая порнография, без разницы в отношении возраста привлеченных лиц [14].

Статья 301 Уголовного кодекса Украины за ввоз, изготовление, сбыт и распространение материалов порнографрического характера предусматривает наказание в виде штрафра от пятидесяти до ста необлагаемых минимумов доходов граждан или ареста на срок до шести месяцев, или ограничение свободы на срок до трех лет. В то же время, те же действия в отношении материалов, содержащих детскую порнографию, или принуждение несовершеннолетних к участию в создании материалов порнографического характера, наказываются лишением свободы на срок от восьми до двенадцати лет с лишением права занимать определенные должности или заниматься определенной деятельностью на срок до трех лет. Также законодательство Украины предусматривает уголовную ответственность за проведение зрелищного мероприятия сексуального характера с участием несовершеннолетнего лица, и за умышленное получение доступа, приобретение, хранение, перемещение детской порнографии без цели ее сбыта или распространения [25, ст. 301, 301', 301²].

Поскольку эти меры направлены на противодействие изготовлению и распространению детской порнографии, что имеет особое значение для защиты детей, особенно актуальным становится вопрос доказательной силы вывода эксперта для избегания возможных противоречий в ходе судебного разбирательства и предотвращения попыток стороны защиты поставить под сомнение утверждение эксперта [26], например, путем указания на некомпетентность экспертаискусствоведа в определении возраста. Экспертная практика в Украине свидетельствует о том, что некоторые эксперты-искусствоведы указывают в заключении выражение «имеются признаки детской порнографии», что фрактически не является доказательством в суде.

Таким образом, категорический вывод о наличии в предоставленных на исследование носителях информации детской порнографии, обоснованный комплексным применением специальных знаний из двух экспертных специальностей - психологии и искусствоведения, является, по нашему мнению, желательным доказательным инструментом обвинения в борьбе с преступлениями сексуального характера против детей, связанных с изготовлением и распространением порнографрии. 


\section{Список литературы}

1. Науково-методичні рекомендації з питань підготовки та призначення судових експертиз та експертних досліджень, затверджені наказом Міністерства юстиції України від 08.10.1998 року № 53/5. Доступно по: https://zakon.rada.gov.ua/laws/show/z0705-98\#Tехt Ссылка активна на 20.03.2021.

2. Бердников Д.В. (2016). Юридические и методологические основы комплексной судебной экспертизы х материалов. Психология и право, 6(1), 18-24.doi:10.17759/psylaw.2016060103.

3. Енгалычев В.Ф., Шипшин,С.С. (1997). Судебно-психологическая экспертиза. Методическое руководство. Калуга. Доступно по: http://yurpsy.com/files/ucheb/engal/013.htm\#2Ссылка активна на 20.03.2021.

4. Карпінська Н. (2017). Проблемні аспекти судової мистецтвознавчої експертизи. Історико-правовий часопис, 2(10), 124-129.

5. Долуда А.О. et al. (2011). Методика судово-експертного мистецтвознавчого дослідження продукції порнографічного характеру. Харків: ХНДІСЕ.

6. Сорокотягина Д.А., Сорокотягин, И.Н. (2014). Комплексные судебные психологические экспертизы и их оценка. Вестник университета имени О.Е. Кутафина (МГЮА), 3, 151-157.

7. Федоров Г.В., Боровик, П.Л. (2012). Использование специальных знаний в форме экспертизы при расследовании оборота детской порнографии. Проблемы правоохранительной деятельности, 2,28-34.

8. Wells M., Finkelhor, D., Wolak, J., Mitchell, K.J. (2007). Defining child pornography: law enforcement dilemmas ininvestigations of Internet childpornography possession. Police Practice and Research, 8(3), 269-282.doi:10.1080/15614260701450765.

9. Kloess J.A.,Woodhams, J.,Whittle,H., Grant, T.,Hamilton-Giachritsis, C.E.(2017). Thechallenges of identifying and classifying child sexual abuse material. Sexual Abuse, 31(2), 173-196.doi:10.1177/1079063217724768.

10. Автономная некоммерческая организация «Судебный Эксперт». Доступно по: https://sudexpa.ru/ expertises/iskusstvovedcheskaia-ekspertiza/ Ссылка активна на 20.03.2021.

11. Центр экспертиз при Институте судебных экспертизи криминалистики. Доступно по: https://ceur.ru/ services/iskusstvovedcheskie-ekspertizy/iskusstvovedcheskaya-ekspertiza/ Ссылка активна на 20.03.2021.

12. Государственный комитет судебных экспертиз РеспубликиБеларусь. Доступно по: https://sudexpert. gov.by/ru/kult_exp.html Ссылка активна на 20.03.2021.

13. Центр судебных экспертиз Министерства юстиции Республики Казахстан. Доступно по: http:// forensic.gov.kz/expertise/view/102/ru Ссылка активна на 20.03.2021.

14. Legality of child pornography. Доступнопо: https://en.wikipedia.org/wiki/Legality_of_child_pornography Ссылка активна на 20.03.2021.

15. What is Child Sexual Abuse Material? Доступно по: https://www.inhope.org/EN/articles/child-sexualabuse-material. Ссылка активна на 20.03.2021.

16. Child Sexual Abuse Material:Model Legislation \& Global Review, 2018 (9th ed.). Alexandria: The Koons Family Institute on International Law \& Policy.

17. New Study Reveals Child Pornography Not a Crime In Most Countries.Доступно по: https://www. icmec.org/press/new-study-reveals-child-pornography-not-a-crime-in-most-countries/. Ссылка активна на 20.03.2021.

18. Child pornography laws in Australia. Доступно по:https://en.wikipedia.org/wiki/Child_pornography_laws_ in_Australia. Ссылка активна на 20.03.2021.

19. Child pornography laws in the Netherlands. Доступно по: https://en.wikipedia.org/wiki/Child_ pornography_laws_in_the_Netherlands. Ссылка активна на 20.03.2021.

20. Закон України «Про захист суспільної моралі» від 20.11.2003 № 1296-IV. Доступнопо: https://zakon. rada.gov.ua/laws/show/1296-15\#Text. Ссылка активна на 20.03.2021.

21. Уголовный кодекс Российской Федерации от 13.06.1996 № 63-Ф3, статья 242.1. Изготовление и оборот материалов или предметов с порнографическими изображениями несовершеннолетних 
Доступно по: http://www.consultant.ru/document/cons_doc_LAW_10699/23ac064057d5bca23505087 2f65b23a1a1db092a/Ссылка активна на 20.03.2021.

22. Конвенція про кіберзлочинність від 23.11.2001. Доступно по: https://zakon.rada.gov.ua/laws/ show/994_575\#ТехtСсылка активна на 20.03.2021.

23. Леонтьев А.Н. (2001). Лекции по общей психологии. Москва: Смысл.

24. Інструкція про призначення та проведення судових експертиз та експертних досліджень, затверджена наказом МіністерстваюстиціїУкраїнивід 08.10.1998 року № 53/5.Доступно по: https://zakon.rada. gov.ua/laws/show/z0705-98\#ТехtСсылка активна на 20.03.2021.

25. Кримінальний кодекс України від 5.04.2001 № 2341-III. Доступно по: https://zakon.rada.gov.ua/laws/ show/2341-14\#ТехtСсылка активна на 20.03.2021.

26. Журавльова М.О. (2017). Щодо «неєвропейського» ставлення до висновків судово-психологічної експертизи. Доступно по: https://protocol.ua/ua/shchodo_neevropeyskogo_stavlennya_do_visnovkiv_ sudovo_psihologichnoi_ekspertizi/Ссылка активна на 20.03.2021.

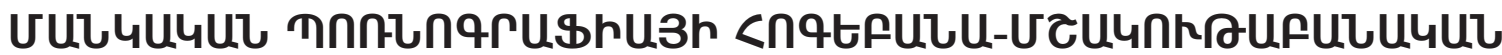

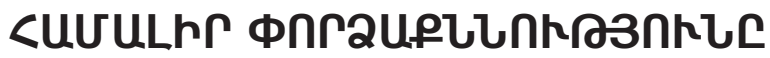

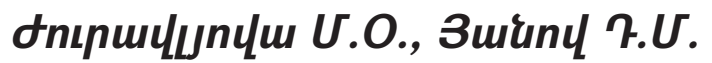

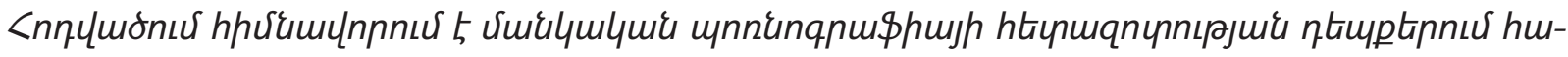

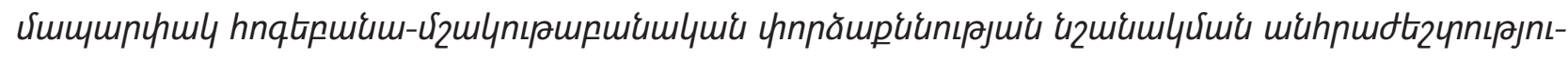

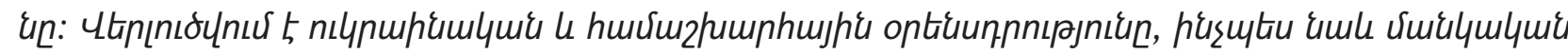

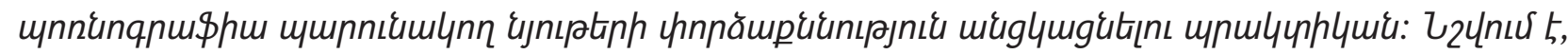

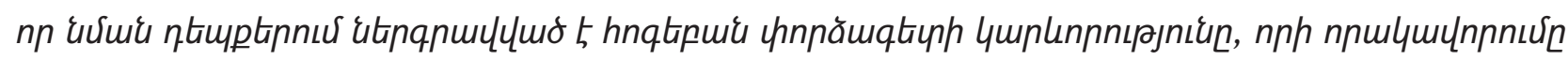

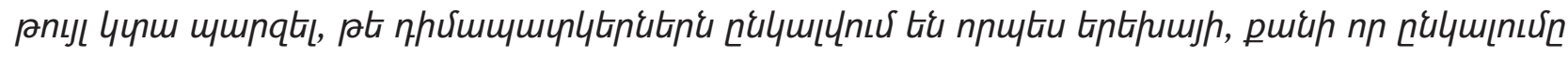

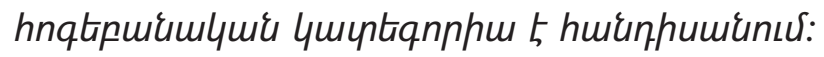

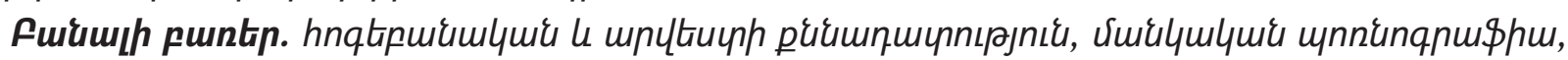
цйumınıर:

\section{COMPLEX PSYCHOLOGICAL AND ART EXPERTISE OF CHILD PORNOGRAPHY}

\section{Zhuravleva M., Yanov D.}

The article substantiates the need for appointment of complex psychological and art expertise in cases of child pornography examination. Ukrainian and world legislation and the practice of examination of materials containing child pornography are analyzed. The importance of involving a psychologist expert in such cases is emphasized, whose qualification allows determining whether the depicted persons are perceived as children, since perception is a psychological category.

Key words: psychological and art expertise, child pornography, perception.

Статья поступила: 30.03.2021

Принята к печати: 10.04.2021 